\title{
Youth Engaging for Success (YES)-Youth peer mentor in-service training: Youth peer mentor guide
}

Project SOAR

Follow this and additional works at: https://knowledgecommons.popcouncil.org/departments_sbsr-hiv

Part of the Public Health Education and Promotion Commons How does access to this work benefit you? Let us know!

\section{Recommended Citation}

Project SOAR. 2019. "Youth Engaging for Success (YES)-Youth peer mentor in-service training: Youth peer mentor guide." Washington, DC: Project SOAR. 


\section{Youth Engaging for Success (YES)}

\section{Youth Peer Mentor \\ In-Service Training}

\section{Youth Peer Mentor Guide}
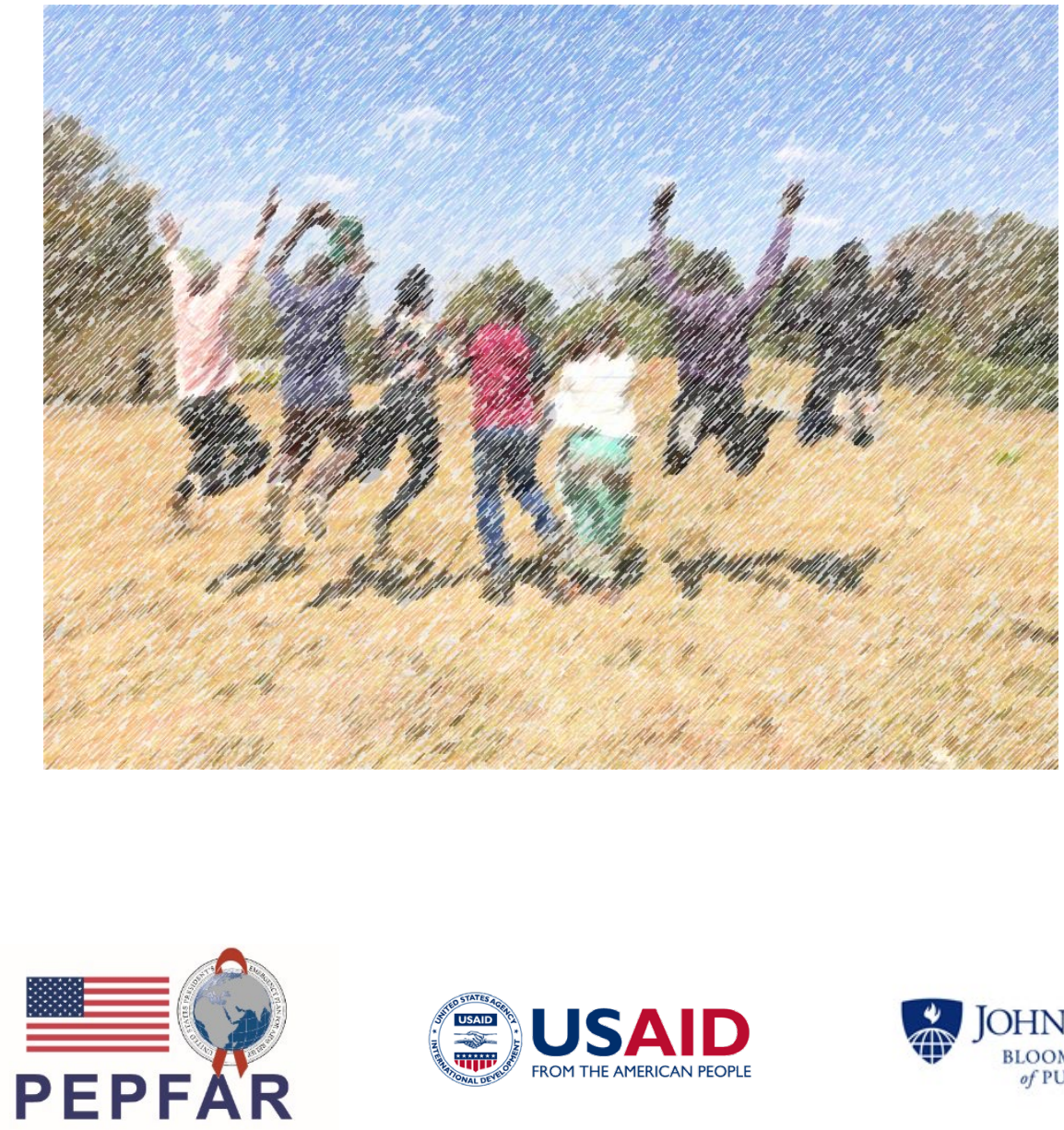


\section{Acknowledgements}

\section{Lead Instructional Designer}

Teresa Peterson - Consultant for Johns Hopkins Bloomberg School of Public Health, Baltimore

\section{Technical Reviewers}

Elizabeth Abrams - Johns Hopkins Bloomberg School of Public Health, Baltimore Virginia Burke - Johns Hopkins Bloomberg School of Public Health, Baltimore

Dr. Julie A. Denison - Johns Hopkins Bloomberg School of Public Health, Baltimore

Christy Frimpong - Project YES

Christine Jere - Project YES

Lindy Mbando - Project YES

Dr. Sam Miti - Arthur Davison Children's Hospital, Ndola

Dr. Jonathan Mwansa - Arthur Davison Children's Hospital, Ndola

\section{Sources of Support}

Project SOAR (Supporting Operational AIDS Research), Cooperative Agreement AID-OAA-A14-00060, is made possible by the generous support of the American people through the President's Emergency Plan for AIDS Relief (PEPFAR) and the United States Agency for International Development (USAID). Led by the Population Council, Project SOAR is implemented in collaboration with Avenir Health, Elizabeth Glaser Pediatric AIDS Foundation, Johns Hopkins University, Palladium, and The University of North Carolina. However, the contents of this curriculum are the sole responsibility of Project SOAR, the Population Council, and the authors and do not necessarily reflect the views of PEPFAR, USAID, or the United States Government.

The project team wishes to acknowledge and thank the people and organizations on the ground that helped to make this project possible, including the Zambia Ministry of Health, Provincial Health Office, Arthur Davison Children's Hospital (ADCH), Ndola Central Hospital $(\mathrm{NCH})$, Twapia Clinic, Lubuto Clinic, and Ndola District Health Management.

Finally, the team extends heartfelt thanks to all of the young people living with HIV who, by participating in this project, have contributed to expanding our knowledge of how best to serve this population.

\section{Version Date: 19 April 2019}




\section{Table of Contents}

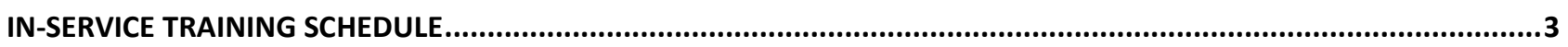

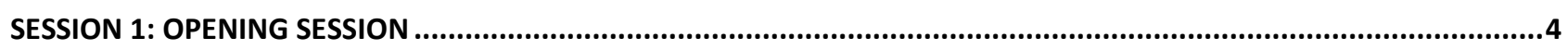

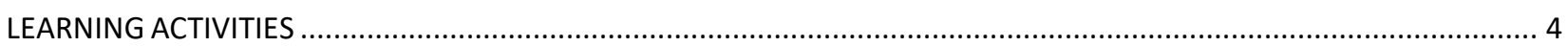

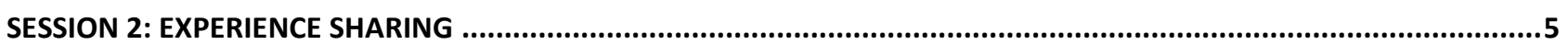

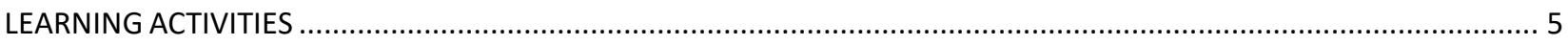

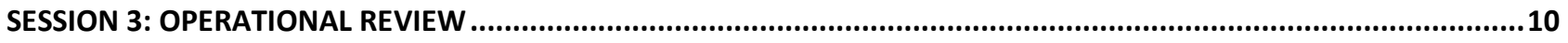

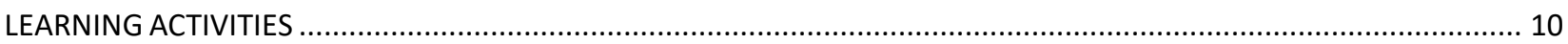

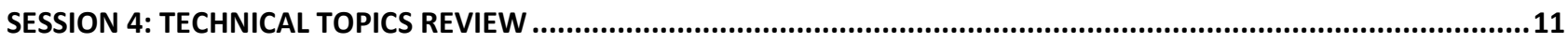

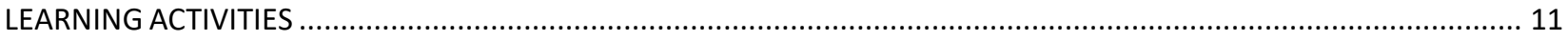

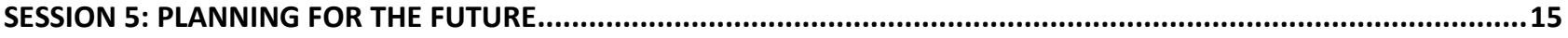

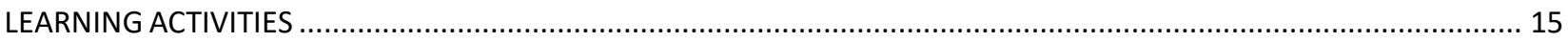

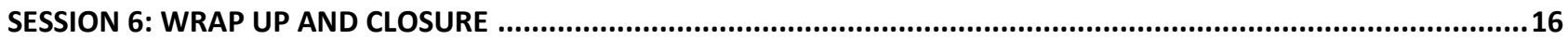

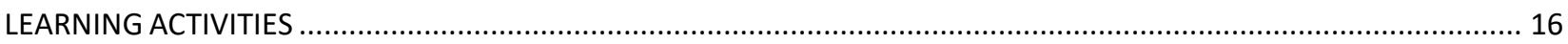




\section{In-Service Training Schedule}

Topics covered in this In-Service Training were determined through a needs assessment questionnaire completed by YPMs and Project YES Staff.

\section{Day 1}

Session 1: Opening Session (1 hour)

08h30-09h30

Session 2: Experience Sharing (1 hour). .09h30-10h30

Tea Break $10 h 30-10 h 45$

Session 2: Experience Sharing continued (2 hours) $10 \mathrm{~h} 45-12 \mathrm{~h} 45$

Lunch Break $12 \mathrm{~h} 45-13 \mathrm{~h} 45$

Session 2: Experience Sharing continued (1 hour and $45 \mathrm{~min}$ ) $13 h 45-15 h 30$

Tea Break $15 \mathrm{~h} 30-15 \mathrm{~h} 45$

Session 3: Operational Review (1 hour and $10 \mathrm{~min}$ ) $15 \mathrm{~h} 45-16 \mathrm{~h} 55$

Daily Summary and Closure $5 \mathrm{~min}$ ) $16 \mathrm{~h} 55-17 \mathrm{~h} 00$

\section{Day 2}

Daily Preview (5 min) $08 h 30-08 h 35$

Session 4: Technical Topics Review - HIV Basics (1 hour) $.08 \mathrm{~h} 35-09 \mathrm{~h} 35$

Session 4: Technical Topics Review - Use of ARVs and Adherence (1 hour). $09 \mathrm{~h} 35-10 \mathrm{~h} 35$

Tea Break $10 \mathrm{~h} 35-10 \mathrm{~h} 50$

Session 4: Technical Topics Review - Sexual Reproductive Health (2 hours and $10 \mathrm{~min}$ ). 10h50 - $13 \mathrm{~h} 00$ Lunch Break $13 \mathrm{~h} 00-14 \mathrm{~h} 00$

Session 4: Technical Topics Review - Stigma and Disclosure (1 hour and $30 \mathrm{~min}$ ) $14 \mathrm{~h} 00-15 \mathrm{~h} 30$

Tea Break $15 \mathrm{~h} 30-15 \mathrm{~h} 45$

Session 4: Technical Topics Review - Thriving with HIV Review (1 hour and $10 \mathrm{~min}$ ) $15 \mathrm{~h} 45-16 \mathrm{~h} 55$ Daily Summary and Closure (5 $\mathrm{min}$ ) $16 \mathrm{~h} 55-17 \mathrm{~h} 00$

\section{Day 3}

Daily Preview (5 min) $08 \mathrm{~h} 30-08 \mathrm{~h} 35$

Session 4: Technical Topics Review - Subject Matter Expert Q\&A (2 hours) .08h35-10h35

Tea Break $10 \mathrm{~h} 35-10 \mathrm{~h} 50$

Session 5: Planning for the Future - Resource Panel (2 hours and $10 \mathrm{~min}$ ) $10 h 50-13 h 00$ Lunch Break $13 \mathrm{~h} 00-14 \mathrm{~h} 00$

Session 5: Planning for the Future - Next Step Planning (1 hour and $30 \mathrm{~min}$ ). $14 \mathrm{~h} 00-15 \mathrm{~h} 30$

Tea Break $15 \mathrm{~h} 30-15 \mathrm{~h} 45$

Session 5: Planning for the Future - Next Step Planning continued (30 min) $15 h 45-16 h 15$ Session 6: Wrap up and Closure (45 min) $16 \mathrm{~h} 15-17 \mathrm{~h} 00$ 


\section{Session 1: Opening Session}

\section{Total Session Time: 1 hour}

\section{OBJECTIVES:}

By the end of the session participants will be able to

- discuss the goal and objectives of the inservice training (IST),

- address questions and expectations about the IST,

- establish ground rules for working together, and

- identify questions on technical and operational topics.
SESSION OVERVIEW

\begin{tabular}{|l|l|}
\hline \multicolumn{1}{|c|}{ Learning Activity } & Time \\
\hline Welcome & $15 \mathrm{~min}$ \\
\hline IST Overview & $15 \mathrm{~min}$ \\
\hline $\begin{array}{l}\text { Technical and Operational } \\
\text { Review Questions }\end{array}$ & $30 \mathrm{~min}$ \\
\hline
\end{tabular}

\section{LEARNING ACTIVITIES}

\section{IST Overview}

\section{IST Goal}

The overall goal of this IST is to increase the capacity of Youth Peer Mentors to deliver effective peer mentoring services to Project YES clients.

\section{IST Objectives}

The specific objectives of this PST are to enable YPMs to

- review foundational knowledge and skills covered in pre-service training,

- receive coaching on challenging client interactions,

- explore answers to questions on HIV-related technical and Project YES operational topics,

- share promising practices, and

- reflect on personal development and plan for future goals.

\section{Expectations}

Write at least one expectation you have for this IST on a sticky note. If you have more than one expectation, write each one on a sticky note.

\section{Technical and Operational Review Questions}

Write specific questions you have about any of the technical or operational topics identified during the needs assessment process on a sticky note and post it on the relevant flip chart. 


\section{Session 2: Experience Sharing}

\section{Total Session Time: 4 hours and 45 minutes}

\section{OBJECTIVES:}

By the end of the session participants will be able to

- work through challenging client interaction scenarios,

- review key communication tools and peer mentoring practices,

- $\quad$ practice identifying interaction content to include in client notes,

- $\quad$ share promising practices, and

- use a self-reflection activity to assess self-care practices.

\section{SESSION OVERVIEW}

\begin{tabular}{|l|l|}
\hline \multicolumn{1}{|c|}{ Learning Activity } & Time \\
\hline Session Overview & 5 min \\
\hline Exploring Client Interactions & $280 \mathrm{~min}$ \\
\hline
\end{tabular}

\section{LEARNING ACTIVITIES}

\section{Exploring Client Interactions}

Consider the following points as you observe each role play.

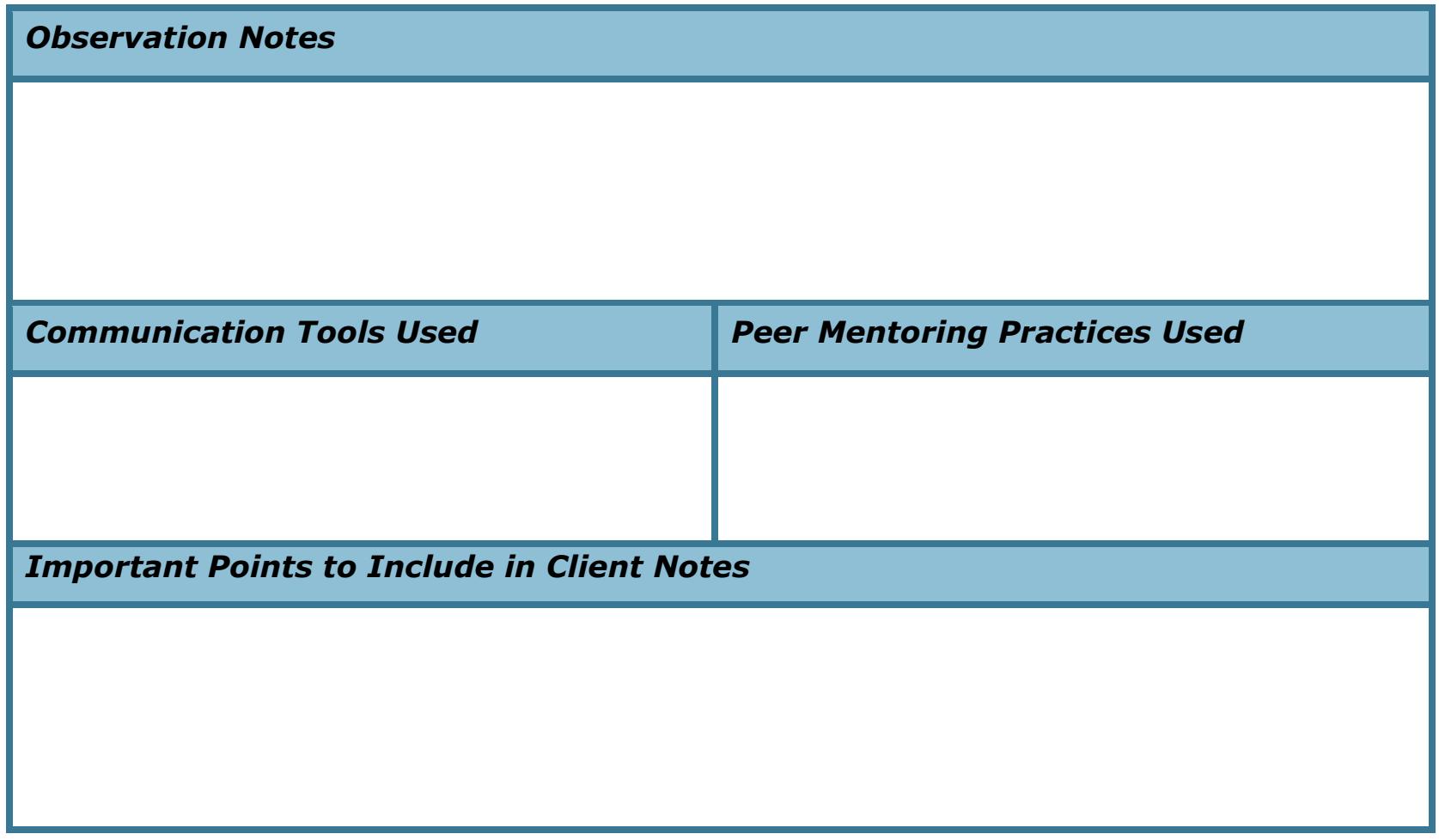




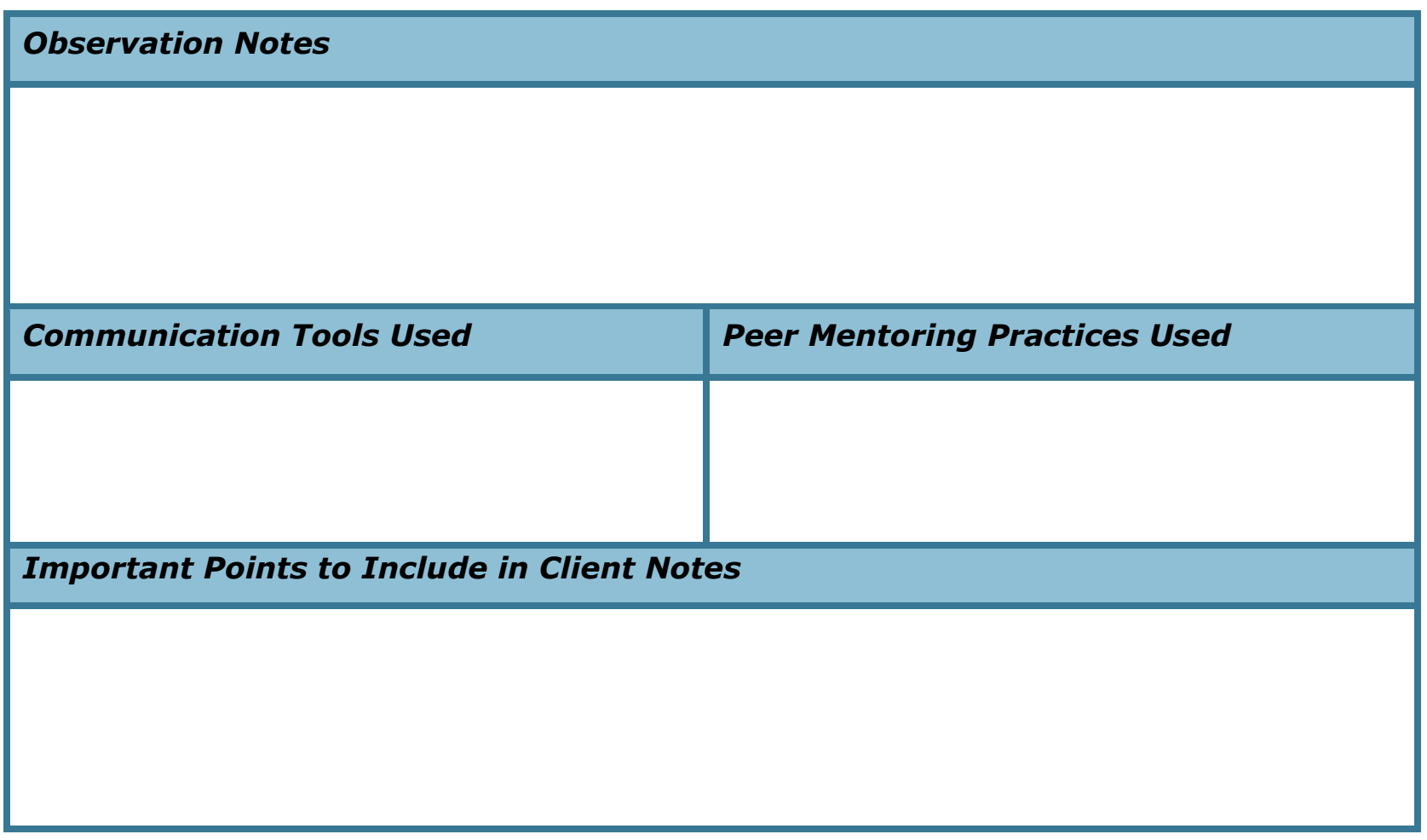

\section{Observation Notes}

Communication Tools Used

Peer Mentoring Practices Used

Important Points to Include in Client Notes 


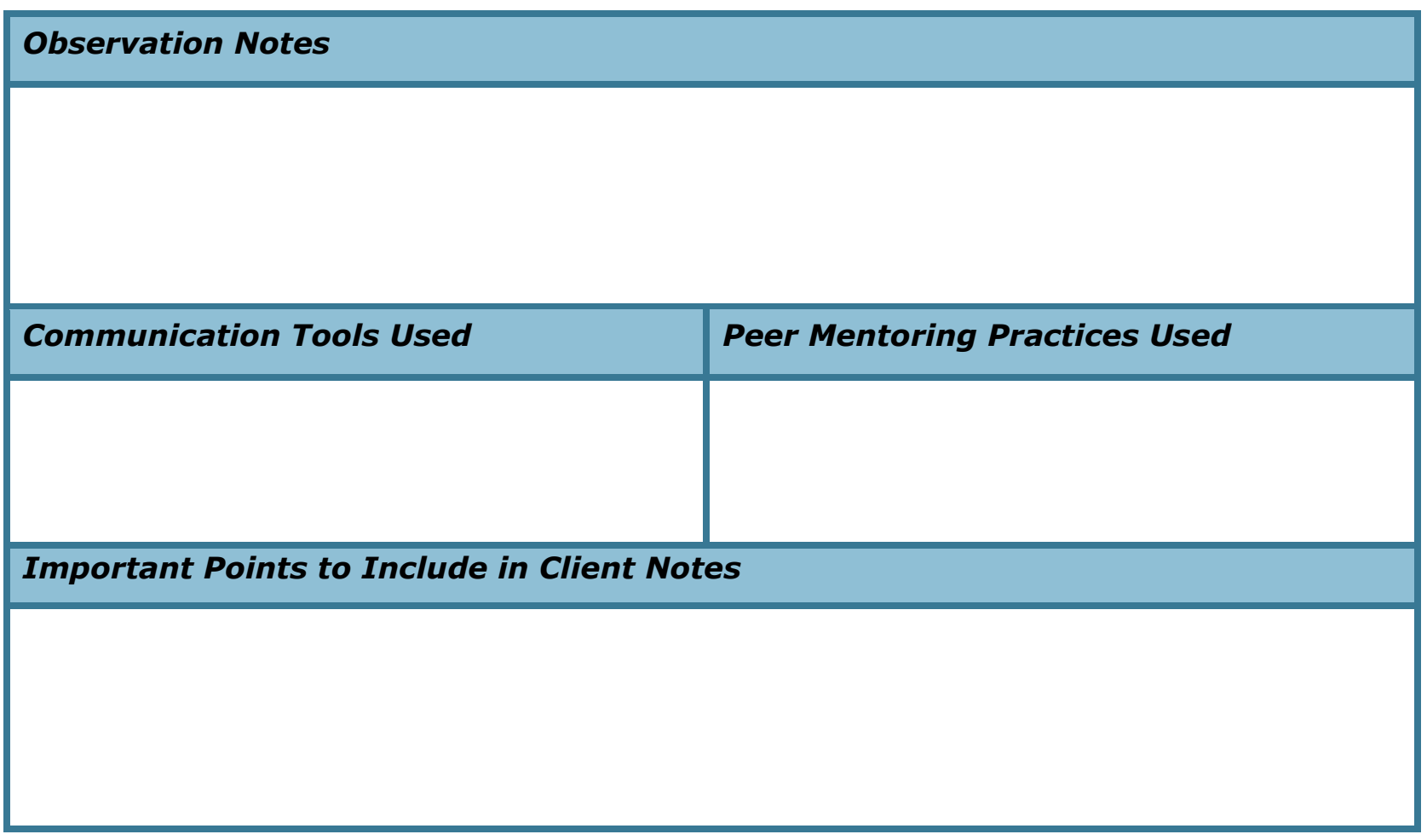

\section{Observation Notes}

Communication Tools Used

Peer Mentoring Practices Used

Important Points to Include in Client Notes 


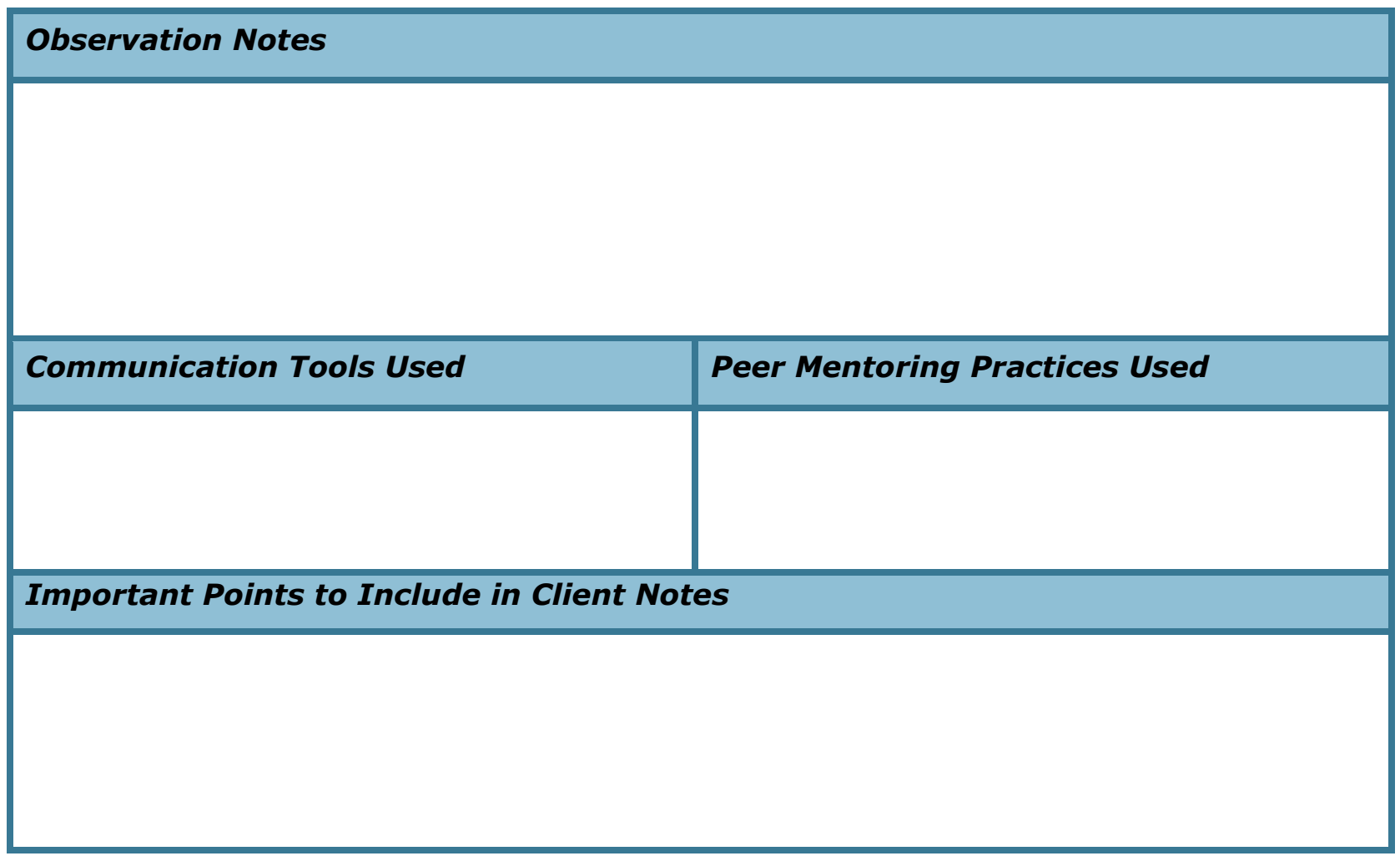

\section{Observation Notes}

Communication Tools Used $\quad$ Peer Mentoring Practices Used

Important Points to Include in Client Notes 


\section{Observation Notes}

Communication Tools Used

Peer Mentoring Practices Used

Important Points to Include in Client Notes

Notes: 


\section{Session 3: Operational Review}

\section{Total Session Time: 1 hour and 10 minutes}

\section{OBJECTIVES:}

By the end of the session participants will be able to

- review Project YES operational policies and procedures,

- obtain answers to operational questions,

- identify potential changes to the client meeting outlines, and

- identify operational issues that need further discussion or consultation with the research team.

\section{SESSION OVERVIEW}

\begin{tabular}{|l|l|}
\hline \multicolumn{1}{|c|}{ Learning Activity } & \multicolumn{1}{c|}{ Time } \\
\hline Session Overview & 5 min \\
\hline Operational Review & 65 min \\
\hline
\end{tabular}

\section{LEARNING ACTIVITIES}

\section{Operational Review}

Notes: 


\section{Session 4: Technical Topics Review}

\section{Total Session Time: 8 hours and 50 minutes}

\section{OBJECTIVES:}

By the end of the session participants will be able to

- review foundational knowledge on HIVrelated topics, and

- obtain answers to questions on HIVrelated technical topics.

\section{SESSION OVERVIEW}

\begin{tabular}{|l|l|}
\hline \multicolumn{1}{|c|}{ Learning Activity } & \multicolumn{1}{c|}{ Time } \\
\hline Session Overview & $5 \mathrm{~min}$ \\
\hline HIV Basics & $55 \mathrm{~min}$ \\
\hline Use of ARVs and Adherence & $60 \mathrm{~min}$ \\
\hline Sexual Reproductive Health & $130 \mathrm{~min}$ \\
\hline Stigma and Disclosure & $90 \mathrm{~min}$ \\
\hline Thriving with HIV & $70 \mathrm{~min}$ \\
\hline $\begin{array}{l}\text { Q\&A with Subject Matter } \\
\text { Expert }\end{array}$ & $120 \mathrm{~min}$ \\
\hline
\end{tabular}

\section{LEARNING ACTIVITIES}

\section{HIV Basics}

Notes: 


\section{Use of ARVs and Adherence}

Notes:

\section{Sexual Reproductive Health}

Notes: 


\section{Stigma and Disclosure}

Notes:

\section{Thriving with HIV}

Notes: 


\section{Q\&A with Subject Matter Experts}

Notes: 


\section{Session 5: Planning for the Future}

\section{Total Session Time: 4 hours and 10 minutes}

\section{OBJECTIVES:}

By the end of the session participants will be able to

- identify local resources providing job skills training, job search, and continuing education support services,

- reflect on experiences as a YPM to identify knowledge, skills, and experience gained,

- explore differences in self-perception as a young person living with HIV, and

- identify post-employment goals and develop an action plan for a selected goal.

\section{SESSION OVERVIEW}

\begin{tabular}{|l|l|}
\hline \multicolumn{1}{|c|}{ Learning Activity } & \multicolumn{1}{c|}{ Time } \\
\hline Session Overview & 5 min \\
\hline Resource Panel & 125 min \\
\hline Next Step Planning & 120 min \\
\hline
\end{tabular}

\section{LEARNING ACTIVITIES}

\section{Resource Panel}

Notes:

\section{Next Step Planning}

Notes: 


\section{Session 6: Wrap Up and Closure}

\section{Total Session Time: 45 minutes}

\section{OBJECTIVES:}

By the end of the session participants will be able to

- provide feedback on training course, and

- obtain certificates of completion.

\section{SESSION OVERVIEW}

\begin{tabular}{|l|l|}
\hline \multicolumn{1}{|c|}{ Learning Activity } & \multicolumn{1}{|c|}{ Time } \\
\hline Session Overview & $5 \mathrm{~min}$ \\
\hline Training Course Evaluation & $20 \mathrm{~min}$ \\
\hline Coming to Closure & $20 \mathrm{~min}$ \\
\hline
\end{tabular}

\section{LEARNING ACTIVITIES}

\section{Training Course Evaluation}

Notes:

\section{Coming to Closure}

Notes: 